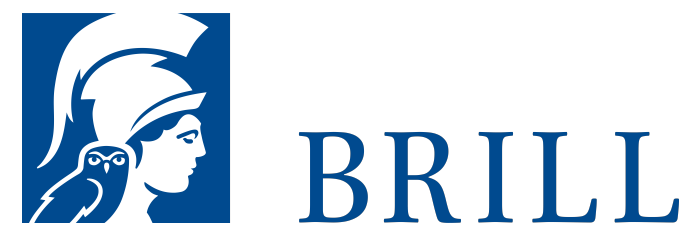

\title{
Moralische Verantwortung
}

Beiträge zur Analyse eines ethischen Begriffs

Author: Otto Neumaier

In der vorliegenden Arbeit wird der Versuch unternommen, folgende Frage zu beantworten: Welche Bedingungen sind notwendig dafür, dass es objektiv gerechtfertigt ist, jemandem moralische Verantwor-tung im Sinne einer Pflicht zuzurechnen? Durch die Beantwortung dieser Frage soll ein kleiner, aber wesentlicher Bereich der Verantwortungsproblematik geklärt werden. Dies zu tun, erscheint allein schon deshalb notwendig, weil die Häufigkeit, mit welcher die Ausdrücke 'verantwortlich' und 'Verantwortung' verwendet werden, mit einer gewissen Unbestimmtheit in Bezug darauf einher geht, was damit jeweils gemeint sein könnte. Diese Unbestimmtheit betrifft nicht zuletzt die Fragen, ob sich die Rede von jemandes Verantwortung auf eine Pflicht der betreffenden Person bezieht oder nicht und ob eine solche Pflicht als moralische Angelegenheit zu sehen ist oder als eine des Rechts oder anderer Normsysteme. Um moralische Verantwortung im Sinne einer Pflicht zu bestimmen, ist insbesondere notwendig, die Bedingungen anzugeben, die erfüllt sein müssen, damit es objektiv gerechtfertigt ist, jemandem Verantwortung im Allgemeinen zuzurechnen, andererseits aber ist zu klären, in welchem Sinne sich Menschen dabei auf Moral berufen. Eine solche Analyse ist notwendig, um zu erkennen, auf welche Weise die Rede von moralischer Verantwortung in unser Leben eingreifen kann und soll.

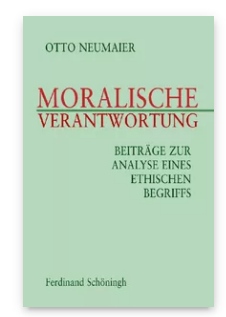

Pages: 269

Seiten

Language:

German

Subjects:

General,

Philosophy

Publisher: Brill |

Schöningh

E-Book (PDF)

Released online:

O2 Dec 2019

ISBN: $978-3^{-}$

657-76504-1

List price

USD $\$ 63.00$

Paperback

Publication date:

21 May 2008

ISBN: 978-3-

506-76504-8

List price

USD $\$ 63.00$ 
For more information see brill.com

Order information: Order online at brill.com +44330 333 0049 | customerservices@brill.com Submission information: brill.com/authors

Titles published by Brill | Fink, Brill | mentis or Brill | Schöningh: +49(o)715413279216| brill@brocom.de 